\title{
Assessment of seismic resistance of the reinforced concrete building by nonlinear dynamic method
}

\author{
Oleg Vartanovich Mkrtychev ${ }^{1}$, Marina Sergeevna Busalova ${ }^{2 *}$ \\ ${ }^{1} \mathrm{Head}$ of the Research laboratory "Safety and Seismic Resistance of Structures" Professor of the \\ Department "Strength of Materials" \\ Moscow State University of Civil Engineering (National Research University) 26, Yaroslavskoe \\ Shosse, Moscow, Russia \\ ${ }^{2}$ Engineer of the Research laboratory "Safety and Seismic Resistance of Structures" Moscow State \\ University of Civil Engineering (National Research University) 26, Yaroslavskoe Shosse, Moscow, \\ Russia \\ *marina8busalova@gmail.com
}

Keywords: direct dynamic method, non-linearity, seismic impact, reinforced concrete structures, near-collapse criterion.

\begin{abstract}
The article studies the reaction of the 5-storey reinforced concrete building of the crosssectional wall structural scheme to the seismic impact. Bearing structures of the building were simulated by the three-dimensional finite elements, connecting concrete and reinforcement, in the software application LS-DYNA. The calculation was carried out by the direct dynamic method using the directly integrated equation of motion according to the explicit scheme. Using this method for calculation allows to make calculations in the temporary area and also to take into account the nonlinearities in the analytic model. In particular, the physical non-linearity is taken into account by means of the non-linear diagram of the concrete deformation. To create an adequate analyticdynamic model the authors of the article developed the method allowing to take into account the actual reinforcement of the structure. The research conducted allows to estimate the reaction of the 5-storey reinforced concrete building to the set seismic impact.
\end{abstract}

\section{Introduction}

The base of the edition of SP 14.13330.2014 SNiP II-7-81* “Construction in Seismic Regions” [1] acting since 2015 takes the requirements of the two-level calculation of the seismic impact. The earthquake analysis corresponding to the level of the maximal design earthquake shall be performed according to the near-collapse criterion. It means that the calculation methods shall directly take into account the non-linear character of the structural deformation (physical, geometrical, structural non-linearities). However, now in Russia the corresponding method and verified dynamic model allowing to make calculations at the level of maximal design earthquake are not available. The authors of the article developed the method allowing to take into account the non-linear properties of concrete when making calculations of seismic impact, and also to include the elements of the connection of concrete and reinforcement into the analytical model taking into account the actual reinforcement of the structure.

\section{Setting of problem}

Concrete is a complicated composite material that consists mostly of the filling and the grouting, and at the different impacts its reaction can vary from brittle fracture at tensioning to yield behavior at compression. Non-linear diagram of concrete deformation taking into account the physical nonlinearity is shown in the Figure 1 [2]. 


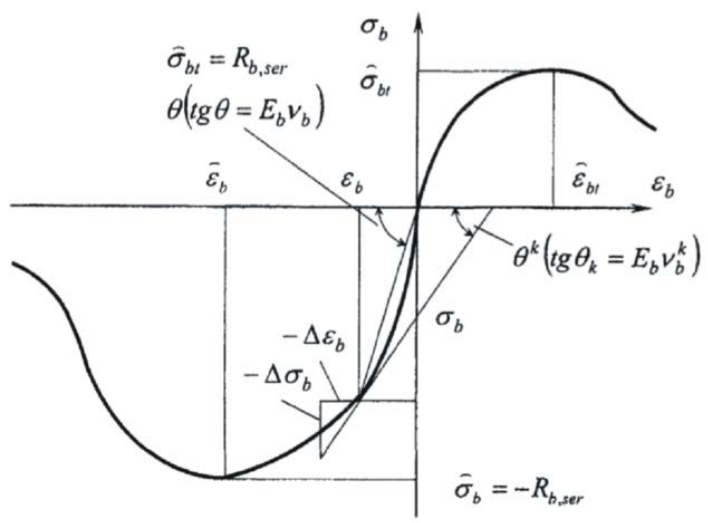

Figure 1. Non-linear diagram of concrete deformation

To solve the problem it is necessary to have a corresponding material model. The Figure 2 shows the most complete models describing adequately the work of concrete at deformation (CSCM Continuous Surface Cap Model) [3].
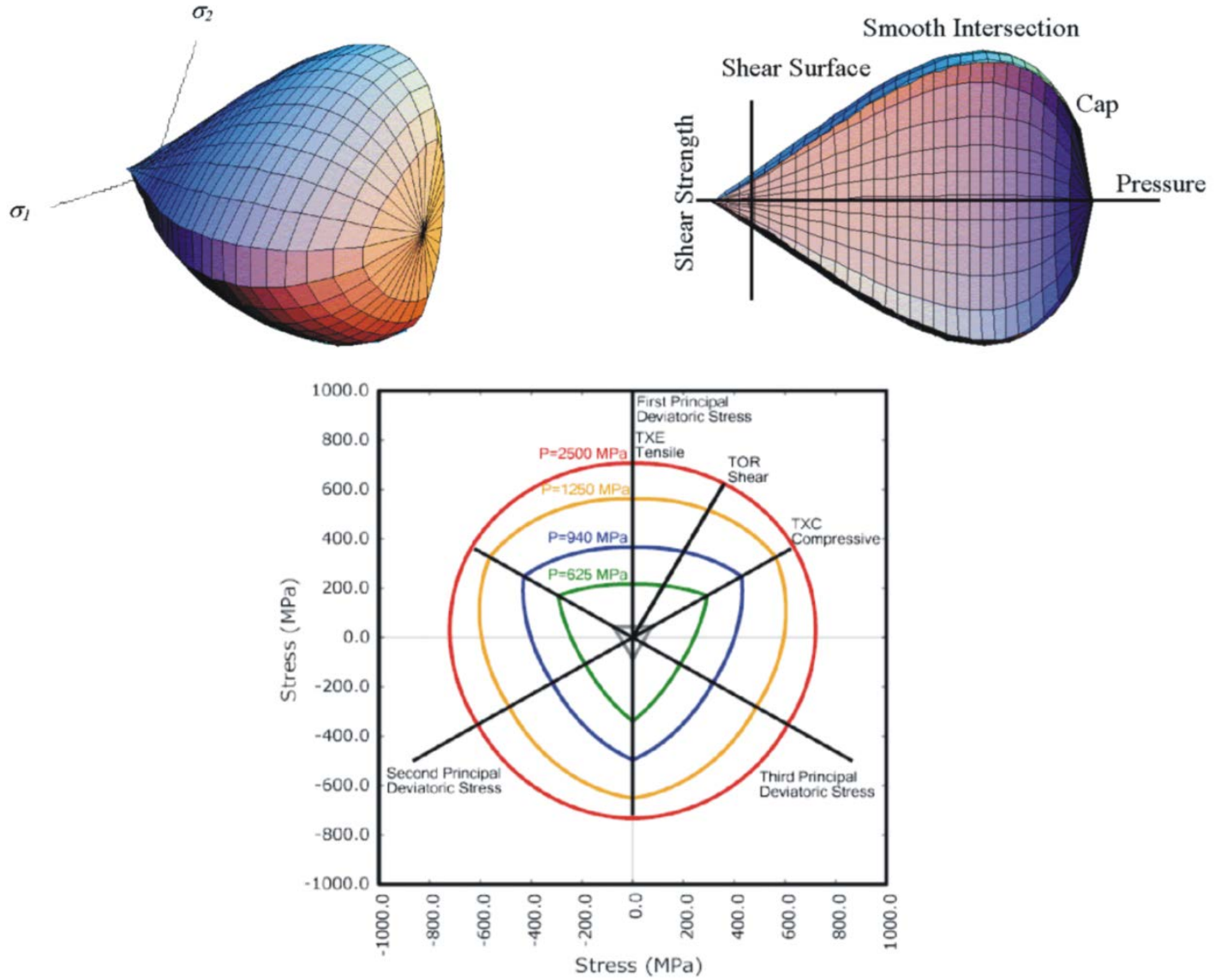

Figure 2. Mathematical model of concrete (CSCM - Continuous Surface Cap Model) Concrete yield surface is described by the invariants of the stress tensor that in turn are determined from the formula (1)-(3).

$$
\begin{aligned}
J_{1} & =3 P \\
J_{2}^{\prime} & =\frac{1}{2} S_{i j} S_{i j} \\
J_{3}^{\prime} & =\frac{1}{3} S_{i j} S_{j k} S_{k i}
\end{aligned}
$$

where $J_{1}$ is the first invariant of the stress tensor, $J_{2}^{\prime}$ is the second invariant of the stress tensor, $J_{3}^{\prime}$ is the third invariant of the stress tensor, $S_{i j}$ is stress tensor, $P$ is pressure.

To study the actual reaction of the structure to the seismic impact it will not be sufficient to take into account the nonlinear properties of the concrete only. To show the real picture of the 
deformation it is necessary to include the actual reinforcement into the analytic dynamic model, that is, to simulate the reinforcement cage of the building under analysis in the structural design [4].

The Figure 3 shows the structural design of the five-storey reinforced concrete building of the cross-sectional wall structural scheme. All bearing structures are simulated by the three dimensional elements for concrete and bar elements for reinforcement [5].

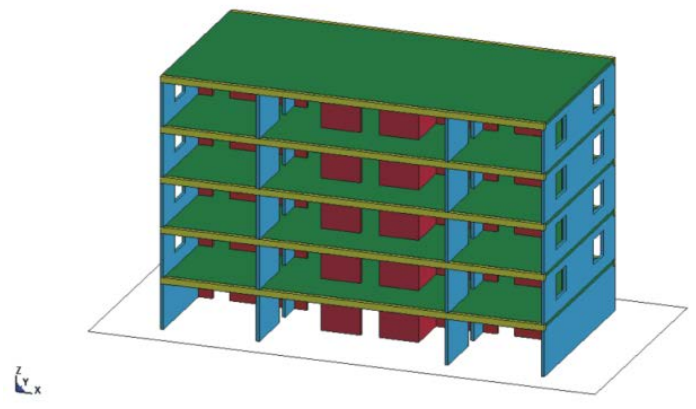

Figure 3. Structural design

The Figure 4 shows the reinforcement cages of the building.
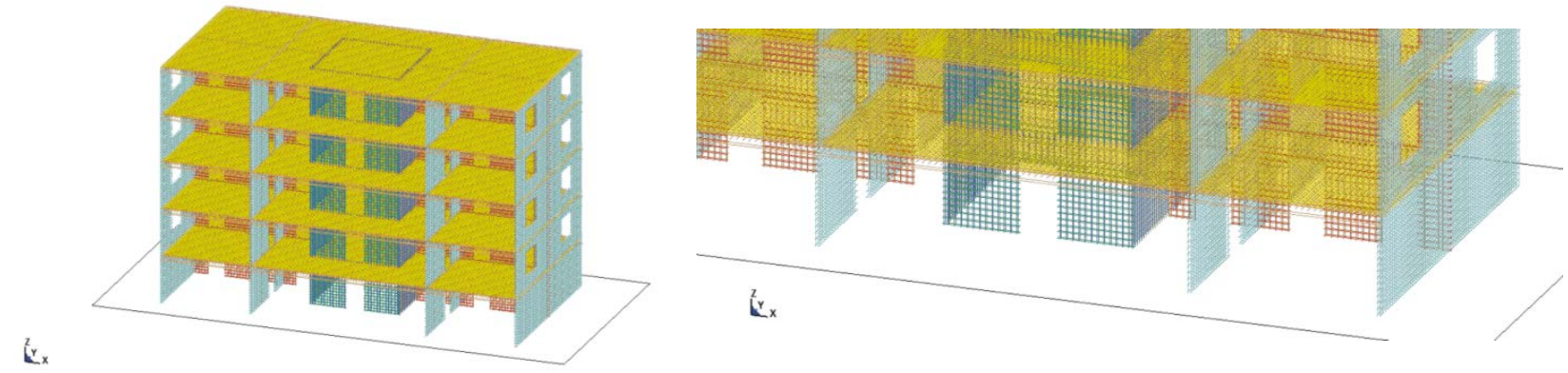

Figure 4. Reinforcement cage

\section{Calculation results}

Calculation was made by the software application LS-DYNA by the direct dynamic method [6]. Equations of motion (4) were integrated directly according to the explicit scheme (5):

$$
\mathbf{M} \ddot{\mathbf{u}}+\mathbf{C} \dot{\mathbf{u}}+\mathbf{K u}=\mathbf{f}^{a}
$$

where $\mathbf{u}$ is nodal displacement vector, $\dot{\mathbf{u}}=\mathbf{v}$ is nodal velocity vector, $\ddot{\mathbf{u}}=\mathbf{a}$ is nodal acceleration vector, $\mathbf{M}$ is mass matrix, $\mathbf{C}$ is damping matrix, $\mathbf{K}$ is rigidity matrix, $\mathbf{f}^{a}$ is vector of applied loads.

$$
\mathbf{u}_{t+\Delta t}=\mathbf{u}_{t}+\mathbf{v}_{t+\Delta t / 2} \frac{\Delta t_{t}+\Delta t_{t+\Delta t}}{2}
$$

This method allows to take into account the geometrical, physical and structural nonlinearities and also to make calculations in the temporary area (dynamics in time).

Three-component diagram was used as a design seismic impact corresponding to the intensity 9 earthquake (Figure 5).

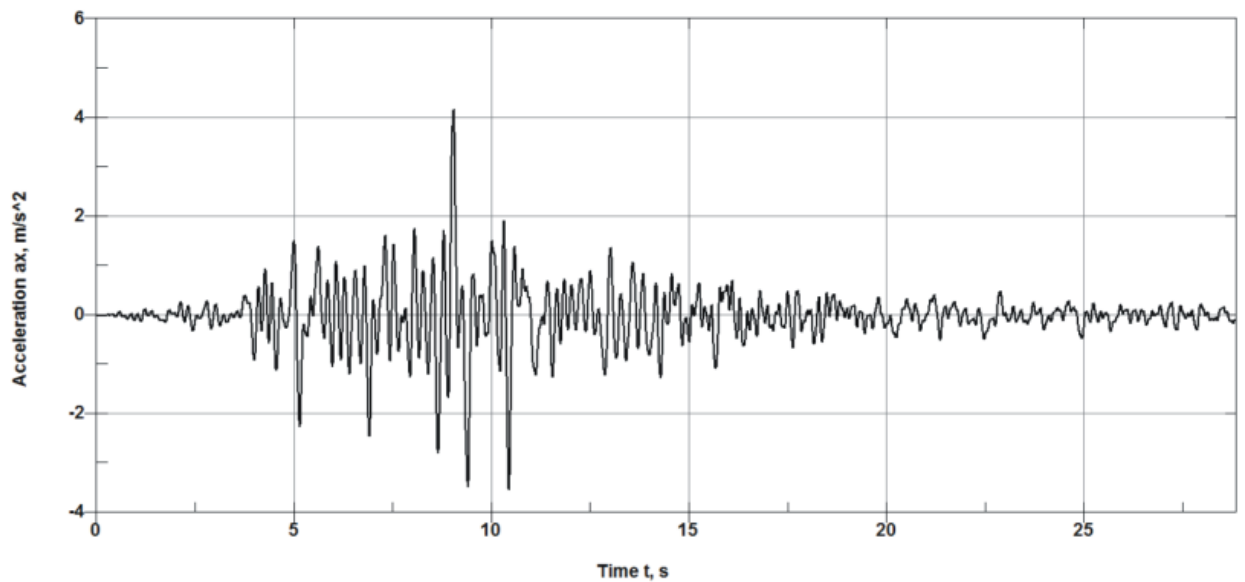




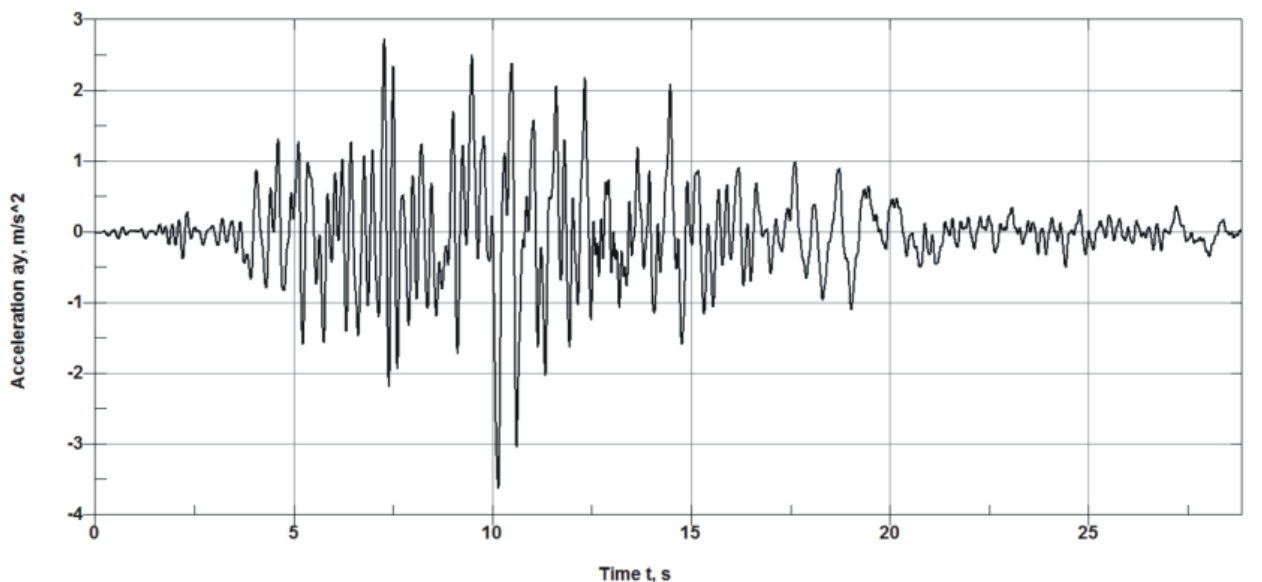

b)

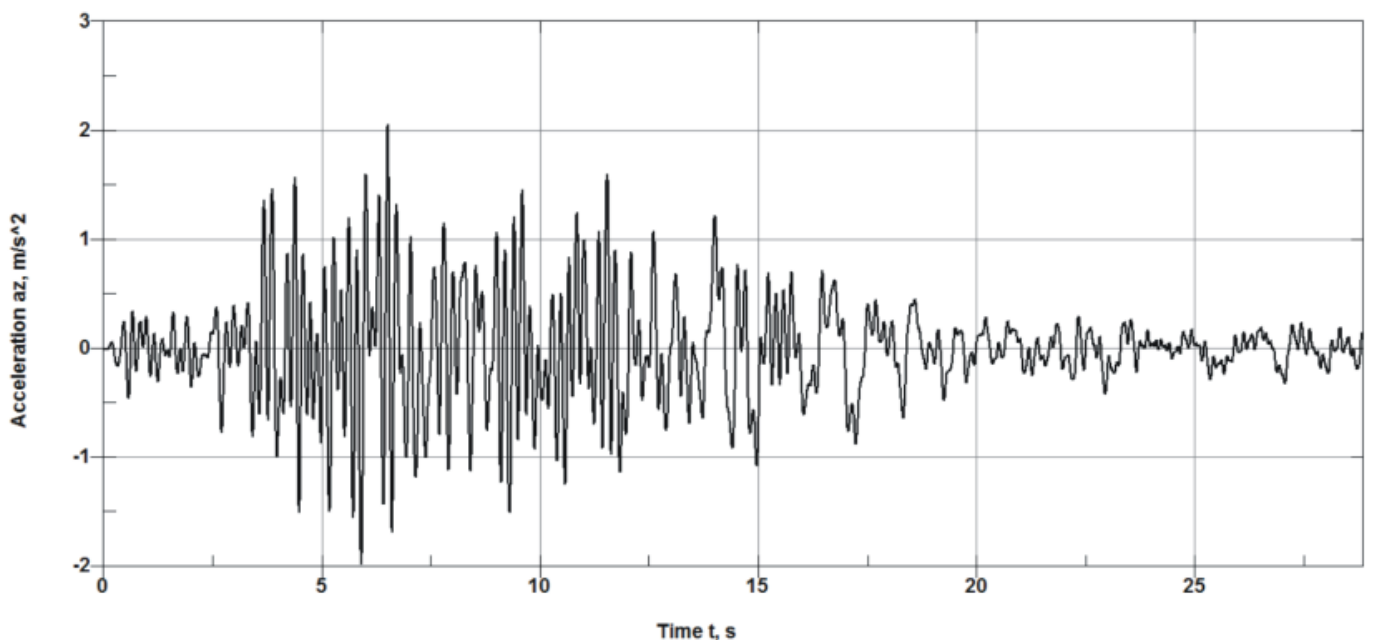

Figure 5. Three-component accelerogram

a) component $X$, b) component $Y$, c) component $Z$

Isofields of the plastic deformations after the earthquake $(t=30 \mathrm{~s})$ are shown in the Figure 6.

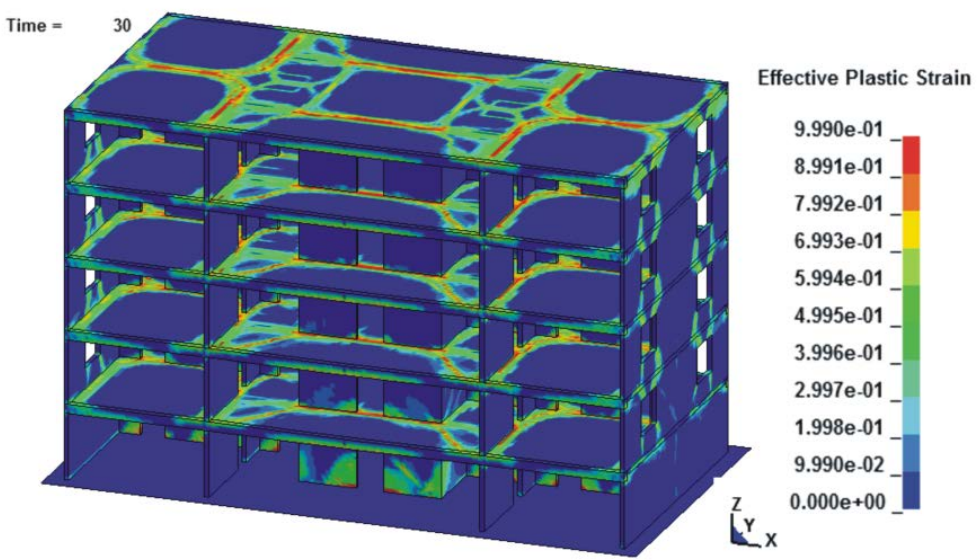

Figure 6. Isofields of the plastic deformations after the earthquake at the moment of time $t=30 \mathrm{~s}$ The character of the plastic deformations corresponds completely to the character of cracks distribution. The Figure 6 shows that the bearing structures of the building of this structural scheme were damaged seriously but the building did not collapse, that means the conditions of the special limit state (near-collapse criterion) are satisfied. As a result of the conducted research, the seismic resistance of the building according to the near-collapse criterion was determined as intensity 9. 


\section{Conclusions}

The analysis of the data obtained as a result of the research allows to conclude that for the adequate estimation of the reaction of the structure to the seismic impact it is necessary to make calculations in the nonlinear dynamic arrangement taking into account the nonlinear diagrams of concrete deformation and also to add the actual reinforcement into the structural design. The use of the offered method of the buildings earthquake calculations at the design stage will allow to estimate adequately the level of seismic resistance of the building structures.

\section{Acknowledgements}

This study was performed with the support of RF Ministry of Education and Science, grant No. $7.2122 .2014 / \mathrm{K}$

\section{References}

[1]. SP 14.13330.2014 SNIP II-7-81. Stroitel'stvo v seysmicheskikh rayonakh [SP 14.13330.2014 SNIP II-7-81. Construction in Seismic Areas]. (2014). Moscow: Analitik.

[2]. SP 63.13330.2012 SNIP 52-01-2003. Betonnye i zhelezobetonnye konstruktsii. Osnovnye polozheniya [SP 63.13330.2012 SNIP 52-01-2003. Concrete and Reinforced Concrete Structures. Summary]. (2012). Moscow: Analitik.

[3]. Murray, Y.D. (2007). Users Manual for LS-DYNA Concrete Material Model 159. Report No. FHWA-HRT-05-062. U.S. Department of Transportation: Federal Highway Administration.

[4]. Murray, Y.D. (2007). Evaluation of LS-DYNA Concrete Material Model 159. Publication No. FHWA-HRT-05-063. U.S. Department of Transportation: Federal Highway Administration.

[5]. LS-DYNA. (n.d.). Keyword User's Manual (Vol. 1, 2). Livermore Software Technology Corporation (LSTC).

[6]. Andreev, V.I., Mkrtychev, O.V., \& Dzinchvelashvili, G.A. (2014). Calculation of Long Span Structures to Seismic and Accidental Impacts in Nonlinear Dynamic Formulation. Applied Mechanics and Materials, 670-671, 764-768 